\title{
CLUSTER ANALYSIS FOR THE DETERMINATION OF INNOVATIVE AND SUSTAINABLE ORIENTED REGIONS IN EUROPE
}

\author{
Associate Professor Corina Pelau PhD \\ Bucharest University of Economic Studies, Romania \\ E-mail: corina.pelau@fabiz.ase.ro \\ Alexandra-Catalina Chinie \\ Bucharest University of Economic Studies, Romania \\ E-mail: alexandra.chinie@gmail.com
}

(Received: March 2018; Accepted: May 2018)

\begin{abstract}
In the past decades the preoccupation of decision-makers towards innovation and sustainable development has gained a major importance in the policy of most countries in Europe. On one hand, efficient innovation can differentiate a country or a region from another and make a difference in the intense increasing economic, technological and social competition. On the other hand, the orientation towards sustainable development assures a clean and unpolluted, social oriented and healthy environment as a framework for the growth of a country or a region. In many cases, innovation and sustainable development go hand in hand, as innovations contribute to the development of clean technologies, while sustainable societies assure the proper environment and background for stimulating the innovation research. The objective of this research is to determine the cluster of countries in Europe which are rather oriented to innovation or to sustainable development or both and to forecast their future developments and tendencies. In order to achieve this objective, the multivariate cluster analysis was applied with the help of the SPSS program, for data provided by the Eurostat for several innovation, sustainable development and contextual indicators. In a first step, for each of the analyzed countries, the values of the indicators have been collected for the same period and the correlations among them have been determined. In the second phase the number of clusters and the cluster membership of each country was determined, by running the Ward cluster analysis. Based on the results, the characteristics of each cluster of countries was defined.
\end{abstract}

Key words: sustainable development, innovation, cluster analysis, regional development. JEL CLASSIFICATION: O30, Q01.

\section{Introduction}

Although sustainable development has been a key interest point since the Brundtland Commission in 1987, global challenges still need to be tackled (Hutt, 2016). In September 2015, a new set of sustainable development goals was adopted

DE GRUYTER Studia Universitatis "Vasile Goldis" Arad. Economics Series Vol 28 Issue 2/2018

OPEN ISSN: 1584-2339; (online) ISSN: 2285-3065 
Pelau, C., Chinie, A. C. (2018)

Cluster analysis for the determination of innovative and sustainable oriented

regions in Europe

by UN Member States, which can be managed by both developed and developing countries (UN General Assembly, 2015). In order to manage sustainable development, the European Council has adopted a strategy in Gothenburg in 2001, which was renewed in June 2006. The strategy has established several directions such as climate change and clean energy, sustainable transport, sustainable consumption and production, conservation and management of natural resources, public health, social inclusion, demography and migration, as well as global poverty and sustainable development challenges (Eurostat, 2016a).

In order to support the Lisbon Strategy for sustainable growth, the European Innovation Scoreboard was developed as an instrument for assessing innovation performance within the European Union and replaced as of 2011 the Innovation Union Scoreboard. The scoreboard uses a framework of indicators which include innovation enablers such as the education level of human resources, research systems, finance and support, firm investments in R\&D and innovation, SMEs innovating in-house, SMEs collaboration, public-private co-publications and intellectual assets, and innovation outputs such as product/process innovations within SMEs, marketing and organizational innovations introduced by SMEs, employment in fast-growing enterprises, and economic effects such as employment in knowledge-intensive activities, medium and high tech product exports, knowledge-intensive services exports, sales of new-to-market and new-to-firm innovations, and license and patent revenues from abroad (European Commission, 2016). The research presented in this paper has as objective the determination of country clusters with similar characteristics based on their innovation and sustainability indicators. Depending on the characteristics of the three determined clusters, different recommendations have been given.

\section{Literature Review}

While organizational, product or process innovation are means of achieving competitive advantage in the case of private companies, innovation has also been linked to sustainable development (Boons et al., 2013), becoming a key element on the agenda of public institutions. From an ecological point of view, supporting the development of the clean energy industry, technological innovation and energy efficiency can contribute to sustainable development objectives, where the environment represents one of the three pillars of sustainable development economic development, social development and environmental protection. Innovation and collaboration between the public and private sectors have been associated with the development of the clean energy industry, as well as the efficient use of resources (Pavlovich and Akoorie, 2010, Turcas et al. 2016). In this 
Pelau, C., Chinie, A. C. (2018)

Cluster analysis for the determination of innovative and sustainable oriented

regions in Europe

regard, scientific literature shows that innovation in the energy sector can be measured in terms of R\&D expenditures and technology patents (Bointner, 2014). According to Bergek et al. (2008), the process of diffusion of a specific technology is reflected in the formation and evolution of technological innovation systems, processes for which both policy makers and entrepreneurial actors play an important part.

According to Sabau (2010), technological innovation shouldn't be treated as being equal to knowledge. In this respect, education has attracted the public interest and has been linked with the achievement of sustainable development goals (Vladimirova and Le Blanc, 2016; Neagu et al. 2017). Creating a knowledge based economy can rely on the level of education of human resources, as well as university publishing - which supports knowledge transfer and academic research, indicators which are assessed through the European Innovation Scoreboard instrument.

\section{Methodology of Research}

The objective of this research is to analyze the similarities and differences regarding the innovation level and sustainability in different countries and to determine clusters of countries with similar behavior. In order to achieve this objective, our research was designed in three phases. The first phase consisted in the collection and preparation of the data. In a second phase the correlations among the indicators has been tested with the help of the factorial analysis, in the SPSS program. In the last phase, three clusters have been determined, also with the help of the SPSS program and the characteristics of the three determined clusters have been analyzed. In the following paragraph, the three mentioned phases are presented in detail.

In order to determine the innovation and sustainability orientation of countries from Europe, in this research, the following indicators from Eurostat and the European Commission were used: for the innovation orientation the source of the eight indicators was the European Innovation Scoreboard (European Commission, 2016); for the sustainability indicators, data from Eurostat Databases (Eurostat 2016b) was used. More details about the indicators can be found in Table 1. All the indicators used in this research were from the year 2014.

Taking into consideration that the range of values for the different indicators differs, the normalized values of the indicators were used in the analysis. Through the normalization, the initial values are rescaled to the interval $[0,1]$, making the data more suitable for several analysis. 
Pelau, C., Chinie, A. C. (2018)

Cluster analysis for the determination of innovative and sustainable oriented regions in Europe

The normalization was done based on the following formula:

$$
X_{N}=\frac{X-X_{\min }}{X_{\max }-X_{\min }}
$$

Where: $\quad X_{N}=$ the normalized value of $X$;

$X=$ the initial value ;

$X_{\min }=$ the minimum value of the $\mathrm{X}$ data set ;

$X_{\max }=$ the maximum value of the $\mathrm{X}$ data set

Table 1. Description of variables

\begin{tabular}{|c|c|}
\hline Indicator & Description \\
\hline Electricity consumption* & $\begin{array}{l}\text { The indicator is defined as the quantity of electricity consumed by } \\
\text { households. Household consumption covers all use of electricity for space } \\
\text { and water heating and all electrical appliances }\end{array}$ \\
\hline Waste Generation* & $\begin{array}{l}\text { The indicator is defined as waste generated in a country per inhabitant and } \\
\text { year, excluding major mineral wastes, dredging spoils and contaminated } \\
\text { soils }\end{array}$ \\
\hline Air pollution* & $\begin{array}{l}\text { The indicator shows the population-weighted concentration of PM10 and } \\
\text { PM2.5 to which the urban population is potentially exposed. }\end{array}$ \\
\hline $\begin{array}{l}\text { Greenhouse gas } \\
\text { emissions* }\end{array}$ & $\begin{array}{l}\text { This indicator shows trends in total man-made emissions of the 'Kyoto } \\
\text { basket' of greenhouse gases. It presents annual total emissions in relation } \\
\text { to } 1990 \text { emissions and also related to emissions in the Kyoto base year. }\end{array}$ \\
\hline Recycling* & $\begin{array}{l}\text { The recycling rate is the tonnage recycled from municipal waste divided } \\
\text { by the total municipal waste arising. }\end{array}$ \\
\hline $\begin{array}{l}\text { New doctorate } \\
\text { graduates** }\end{array}$ & New doctorate graduates per 1000 population aged $25-34$ \\
\hline $\begin{array}{l}\text { Top scientific } \\
\text { publications** }\end{array}$ & $\begin{array}{l}\text { Scientific publications among the top } 10 \% \text { most cited publications } \\
\text { worldwide as } \% \text { of total scientific publications of the country }\end{array}$ \\
\hline $\begin{array}{l}\text { Public R\&D } \\
\text { expenditure }\end{array}$ & Public R\&D expenditures as \% of GDP \\
\hline $\begin{array}{l}\text { Business R\&D } \\
\text { expenditure** }\end{array}$ & Business R\&D expenditures as \% of GDP \\
\hline $\begin{array}{l}\text { PCT patent } \\
\text { applications** }\end{array}$ & PCT patents applications per billion GDP (in PPS $€$ ) \\
\hline $\begin{array}{l}\text { PCT patent applications } \\
\text { in societal challenges } * *\end{array}$ & PCT patent applications in societal challenges per billion GDP (in PPS $€$ ) \\
\hline $\begin{array}{l}\text { Medium and high tech } \\
\text { product exports** }\end{array}$ & Medium and high-tech product exports as \% of total product exports \\
\hline $\begin{array}{l}\text { Knowledge-intensive } \\
\text { services exports** }\end{array}$ & Knowledge-intensive services exports as \% total service exports \\
\hline
\end{tabular}

Source:* Eurostat Database (2016); **European Commission (2016)

DE GRUYTER OPEN
Studia Universitatis "Vasile Goldis" Arad. Economics Series Vol 28 Issue 2/2018 ISSN: 1584-2339; (online) ISSN: 2285 - 3065 
In the second phase, a factor analysis was applied for the normalized data, in order to determine the correlations among the indicators. The Kaiser-Meyer-Olkin criterion value of 0.689 indicates a middling adequacy of the data set for the factor analysis. The values of the main diagonal in the Anti-Image Correlation Matrix also show a high adequacy of the indicators for a factor analysis, showing that for most of the factors there are similarities in the policies and orientations of the European countries. The indicators with a lower measure of sampling adequacy $(\mathrm{MSA})$ were waste generation $(\mathrm{MSA}=0.178)$, greenhouse gas emissions $(\mathrm{MSA}=$ $0.180)$ and medium and high-tech products exports $(\mathrm{MSA}=0.255)$. According to the scree plot, for this data, there is an ideal number of two factors. Analyzing the loadings of the items, a factor containing items like medium and high-tech products exports (0.669), electricity consumption (0.591) and the air pollution (0.314) will be determined. All the other items were grouped in the other factor. Despite these aspects, for the cluster analysis, all indicators were used, without grouping them into factors.

In order to determine the clusters of countries, the Ward Cluster Analysis has been applied. This multivariate clustering method has the advantage that it divides the sample into clusters with similar number of elements (Backhaus, et.al. 2000). The first issue determined in this method is the ideal number of clusters. This can be done on one hand by analyzing the dendogram of the model, which shows in our case an ideal number of two or three clusters. Another method of determining the ideal number of clusters, is the elbow criterion. Therefore, in a system of coordinates we design the graph, having as coordinates the number of clusters ( $\mathrm{x}$ axes) and the sum of the square errors (y-axes). Based on this method, we obtained an ideal number of three clusters. Therefore, with the help of the SPSS program, the cluster membership for the analyzed countries was determined. For each of the clusters and elements of clusters, the F-test and the t-test have been measured. The F-test is a measure which characterizes the homogeneity of a cluster. The lower the value of this indicator, the higher is the homogeneity within the group. A group is considered to be homogenous when the F-values for all the considered factors are lower than 1. F-values higher than 1 indicate the fact that the variable is wider distributed in the cluster in comparison to the whole sample (Backhaus, et.al. 2000).

The formula for the calculation of the F-test is the following:

$$
F=\frac{V(J, G)}{V(J)}
$$

Where: $\quad \mathrm{V}(\mathrm{J}, \mathrm{G})=$ Variance of variable $\mathrm{J}$ in the cluster/ group $\mathrm{G}$ $\mathrm{V}(\mathrm{J})=$ Variance of variable $\mathrm{J}$ in the whole sample OPEN
Studia Universitatis "Vasile Goldis" Arad. Economics Series Vol 28 Issue 2/2018 ISSN: 1584-2339; (online) ISSN: 2285 - 3065

Web: publicatii.uvvg.ro/index.php/studiaeconomia. Pages $36-47$ 
The t-test is a measure which characterizes the overrepresentation or underrepresentation of a factor within a group. If the value of the t-test is higher than 1, it means that the factor has a higher value for the cluster/group in comparison to the whole sample. If the t-test value is negative, it means that the factor is underrepresented in the analyzed cluster/group (Backhaus, et.al. 2000). The formula for the t-test is the following:

$$
t=\frac{X(J, G)-X(J)}{S(J)}
$$

Where: $\quad X(J, G)=$ Average of variable $J$ in the group $G$

$X(J)=$ Average of variable $\mathrm{J}$ in the whole sample

$S(J)=$ Standard deviation of variable $\mathbf{J}$ in the whole sample

In the following section, the three clusters and their characteristics are presented.

\section{Results of the Cluster Analysis}

The results of the cluster analysis show that based on innovation and sustainability indicators, three clusters of European countries can be determined. Based on the characteristics of the three clusters, they have been generically named: Cluster $1-$ Innovative and sustainable countries, Cluster 2 - Clean, innovation improvers and Cluster 3 - Innovation followers and sustainability improvers. The three clusters and their cluster membership can be observed in Table 1 .

In the following paragraphs, the three clusters and their characteristics are presented. The F-test and t-test values for the three clusters can be observed in Table 3 and Table 4.

\section{Cluster 1 - Innovative and sustainable countries}

Countries, which have the highest values for the innovation indicators and average values for the sustainability indicators are included in the first cluster. Therefore, with one exception at the knowledge-intensive services exports (where the value is comparable to the highest value of Cluster 3), the countries in Cluster 1 have the highest innovation indicators. The fact that Cluster 1 has the highest value for all innovation indexes is also confirmed by the t-test, having a higher representation of these factors compared to the whole sample. 
Pelau, C., Chinie, A. C. (2018)

Cluster analysis for the determination of innovative and sustainable oriented

regions in Europe

Table 2. Cluster membership of European countries depending on innovation and sustainability indicators for the year 2014

\begin{tabular}{ccc}
\hline $\begin{array}{c}\text { Cluster 1 - Innovative and } \\
\text { sustainable countries }\end{array}$ & $\begin{array}{c}\text { Cluster 2 - Clean, } \\
\text { innovation improvers }\end{array}$ & $\begin{array}{c}\text { Cluster 3 - Innovation } \\
\text { followers and } \\
\text { sustainability improvers }\end{array}$ \\
\hline Belgium & Bulgaria & Estonia \\
Denmark & Czech Republic & Ireland \\
Germany & Croatia & Greece \\
France & Cyprus & Spain \\
Netherlands & Latvia & Italy \\
Austria & Lithuania & Luxembourg \\
Slovenia & Hungary & Portugal \\
Finland & Malta & Iceland \\
Sweden & Poland & Norway \\
United Kingdom & Romania & \\
\multicolumn{2}{c}{ Source: Cluster Analysis Results based on data from the } \\
European Commission (2016) and Eurostat (2016)
\end{tabular}

For the sustainability indicators used in this research, the countries in Cluster 1 have average values. On one hand they are the heaviest electricity consumers, having an overrepresentation $(t=0.638)$ of this factor compared to the whole sample. Besides this, the electricity consumption has an $\mathrm{F}=1.857$ showing a wider distribution of this factor compared to the whole sample. Cluster 1 has average values of the indicators for waste generation, air pollution and greenhouse emissions compared to the other two clusters. While there is an overrepresentation for waste generation $(t=0.151)$ compared to the whole sample, in the case of air pollution $(\mathrm{t}=-0.360)$ and greenhouse gas emissions $(\mathrm{t}=-0.053)$ there is an underrepresentation. The sustainability index which has the highest value for this cluster is "recycling activities" $(\mathrm{t}=0.950)$. Analyzing the F-test values, it can be observed that the indicators are not necessarily distributed homogenously within this cluster. Most of the F-test values range between 0.311 and 0.488 showing that despite the similarities identified compared to the whole sample, there are still differences in the innovation activities. One of the few indicators which show a higher homogeneity is the greenhouse gas emissions $(F=0.093)$. One possible explanation for these results is the fact that the development and production of innovative products leads to higher consumption of energy and creates higher pollution. Therefore, it is important to support the orientation towards clean, unpolluted, renewable energies in these countries. 


\section{Cluster 2 - Clean, innovation improvers}

In cluster 2, there are included countries which have small values for the innovation indicators and "cleaner" values for sustainability. One reason for this situation can be the fact that having few innovations and high-tech products, they consume less energy and produce less waste. They have been named "innovation improvers" as these countries should stimulate the research and development activities more. These countries were named "clean" as they have the smallest energy consumption $(t=-0.498)$, the fewest waste generation $(t=-0.408)$ and the lowest greenhouse gas emissions $(t=-0.357)$. Despite of these, they have the heaviest air pollution $(t=0.837)$ and the lowest recycling rate $(t=-0.996)$. One may say that the high air pollution can be explained by the lack of innovative technologies. Despite of this, they have also an average high-tech products export $(t=0.169)$ as one of the few indicators, which are overrepresented in the whole sample. As mentioned before, all other indicators are underrepresented in the sample, having a negative $t$-test value $(t<0)$.

In opposition to cluster 1, the F-test has lower values, showing a higher homogeneity of the distribution of indicators. Innovation indicators with a high homogeneity are the patent applications $(\mathrm{F}=0.067)$, patent applications in societal challenges $(\mathrm{F}=0.206)$, business research and development expenditures $(\mathrm{F}=$ $0.199)$ and scientific top publications by citations $(F=0.204)$. Electricity consumption $(\mathrm{F}=0.040)$ and waste generation $(\mathrm{F}=0.112)$ are the homogeneous sustainability indexes. On the other hand, there are also indicators with a higher heterogeneity like medium and high-tech products $(\mathrm{F}=1.061)$ or the greenhouse gas emissions $(\mathrm{F}=1.777)$, which have extreme values within this factor. Analyzing this factor, the recommendation is to sustain and stimulate the activities of research and development. The indicators show a high value of exports for medium and high-tech products, but other indicators are underrepresented in the sample. Regarding the sustainability indexes, a balance among the indicators should be kept.

\section{Cluster 3 - Innovation followers and sustainability improvers}

Countries which have average values for the innovation indicators were included in Cluster 3 and were generically named "innovation followers". Despite the lower innovation values, the countries with the highest average values for the waste generation and greenhouse gas emissions are included in this cluster, and therefore they have been generically named "sustainability improvers".

Despite the average values of the innovation indicators, it can be observed in Table 2 , that there are indicators in this cluster which are overrepresented in comparison 
Pelau, C., Chinie, A. C. (2018)

Cluster analysis for the determination of innovative and sustainable oriented

regions in Europe

to the whole sample. Among these, there are the scientific top publication by citation $(\mathrm{t}=0.321)$ and the public research and development expenditure $(\mathrm{t}=$ 0.038). The innovation indicators are underrepresented in comparison to the whole sample, showing that the countries in Cluster 1 are more advanced in this sense compared to the other two clusters. The only indicator which has the highest average value in the sample is knowledge-intensive services exports $(t=0.485)$. Regarding the sustainability indicators, as mentioned before this cluster has the highest value for the greenhouse gas emissions $(t=0.496)$ and waste generation $(t$ $=0.331)$. Besides, they have an overrepresented value for recycling $(t=0.162)$ and underrepresented values for the electricity consumption $(t=-0.100)$ and air pollution $(\mathrm{t}=-0.667)$.

Similar to Cluster 2, Cluster 3 also has a higher homogeneity among the factors especially for the innovation indicators. The F-test value for these indicators ranges between 0.126 and 0.380 ( $\mathrm{F} \in[0.126,0.380])$. The exceptions are the medium and high-tech product exports $(\mathrm{F}=0.969)$, the knowledge intensive services exports $(\mathrm{F}$ $=0.862)$ and the new doctorate graduates $(\mathrm{F}=0.758)$. Regarding the sustainability indicators, they have a higher heterogeneity, waste generation being the indicator with highest F-test value $(\mathrm{F}=2.438)$ for this cluster.

Table 3. F-Test Values for the three clusters

\begin{tabular}{l|ccc}
\hline & F test & F test & F test \\
& Cluster 1 & Cluster 2 & Cluster 3 \\
\hline Electricity consumption & 1.857 & 0.040 & 0.455 \\
Waste generation & 0.378 & 0.112 & 2.438 \\
Air pollution & 0.388 & 0.739 & 0.479 \\
greenhouse gas emissions & 0.093 & 1.777 & 0.653 \\
Recycling & 0.479 & 0.323 & 0.164 \\
New doctorate graduates per 1000 population & 0.403 & 0.530 & 0.758 \\
Scientific top publications by citation & 0.311 & 0.204 & 0.126 \\
Public R\&D expenditures as \% of GDP & 0.488 & 0.610 & 0.380 \\
Business R\&D expenditures as \% of GDP & 0.394 & 0.199 & 0.127 \\
PCT patents applications per billion GDP & 0.403 & 0.067 & 0.264 \\
PCT patent applications in societal challenges/billion & 0.328 & 0.206 & 0.223 \\
GDP & & & \\
Medium and high-tech product exports & 0.286 & 1.061 & 0.969 \\
Knowledge-intensive services exports & 0.519 & 0.541 & 0.862 \\
\hline Source: Own Calculation based on Cluster Analysis Resile
\end{tabular}

Source: Own Calculation based on Cluster Analysis Results based on data from the European Commission (2016) and Eurostat (2016) 
Pelau, C., Chinie, A. C. (2018)

Cluster analysis for the determination of innovative and sustainable oriented regions in Europe

\section{Table 4. $t$-Test Values for the three clusters}

\begin{tabular}{l|ccc}
\hline & $\begin{array}{c}\text { t-test } \\
\text { Cluster 1 }\end{array}$ & $\begin{array}{c}\text { t-test } \\
\text { Cluster 2 }\end{array}$ & $\begin{array}{c}\text { t-test } \\
\text { Cluster 3 }\end{array}$ \\
\hline Electricity consumption & 0.638 & -0.498 & -0.100 \\
Waste generation & 0.151 & -0.408 & 0.331 \\
Air pollution & -0.360 & 0.873 & -0.667 \\
greenhouse gas emissions & -0.053 & -0.357 & 0.496 \\
Recycling & 0.950 & -0.996 & 0.162 \\
New doctorate graduates per 1000 population & 0.890 & -0.688 & -0.148 \\
Scientific top publications by citation & 0.941 & -1.118 & 0.321 \\
Public R\&D expenditures as \% of GDP & 0.869 & -0.821 & 0.038 \\
Business R\&D expenditures as \% of GDP & 1.196 & -0.826 & -0.320 \\
PCT patents applications per billion GDP & 1.180 & -0.874 & -0.243 \\
PCT patent applications in societal challenges/billion & 1.135 & -0.925 & -0.131 \\
GDP & & & -0.702 \\
Medium and high-tech product exports & 0.446 & 0.169 & 0.485 \\
Knowledge-intensive services exports & 0.443 & -0.799 & \\
\hline
\end{tabular}

Source: Own Calculation based on Cluster Analysis Results based on data from the European Commission (2016) and Eurostat (2016b)

Taking into consideration these aspects, the countries in Cluster 3 should continue and improve their innovation strategy. As it can be observed, there are innovation fields like the knowledge intensive services exports, where these countries have a good position. Regarding the sustainability of the environment, they should try to reduce the negative effects.

\section{Conclusions}

Analyzing the results of the multivariate cluster analysis, it can be observed that there is a combination between innovation and sustainability orientation. On one hand, there is Cluster 1, which is a highly innovative cluster of countries, in detriment of the environmental sustainability. The development and the production of high innovative products consume a high amount of energy and resources, fact that is reflected in the sustainability indicators. On the other hand, there is Cluster 3 , a cluster of innovation followers, which probably are focused more on achieving good innovation results and reduce the gap to Cluster 1 , and therefore are less oriented towards the protection of the environment. Cluster 2 includes countries with low innovation indicators. Results show that the small amount of investments in innovation could preserve the environment. Despite of this, because of the lack of innovation, progress cannot be sustained. The F-test value shows a higher 
Pelau, C., Chinie, A. C. (2018)

Cluster analysis for the determination of innovative and sustainable oriented regions in Europe

homogeneity of Cluster 2 and Cluster 3, which can be explained by the lower absolute values. Also, the factors which have a higher heterogeneity are pointed out by high F-test values.

The analysis for the sustainability characterization of the countries was based only on indicators regarding the environment. The reason for this was the fact that the environmental sustainability is better related to the innovations. Of course, indicators regarding the health system, the quality of life or social inclusion contribute also to the sustainable development of a country, but are less related to innovation. Despite of these they can be included in a future model.

The results of the research may contribute to the development of policies at European level oriented towards achieving a sustainable balance between economic growth, innovations and environmental protection. By having countries clustered based on similar innovation performance and environmental sustainability, decision makers at European level and worldwide can direct specific policies towards each of the regional clusters. These targeted policies can increase the efficiency and efficacy of the measures and of the funding towards these fields. The future research could extend the number of indicators, also considering social inclusion and the quality of life.

\section{References}

1. Backhaus, K.; Erichson, B.; Plinke, W.; Weiber, R. (2000). Multivariate Analysemethoden - Eine anwendungsorientierte Einfuehrung. Berlin: Springer.

2. Bergek, A., Hekkert, M., Jacobsson, S. (2008). Functions in innovation systems: a framework for analyzing energy system dynamics and identifying goals for systembuilding activities by entrepreneurs and policy makers. In: Foxon, T., Köhler, J., Oughton, C. (Eds.), Innovation for a Low Carbon Economy: Economic, Institutional and Management Approaches. Cheltenham: Edward Elgar Publishing.

3. Bointner, R. (2014). Innovation in the energy sector: Lessons learnt from R\&D expenditures and patents in selected IEA countries, Energy Policy, 73, 733-747.

4. Boons, F., Montalvo, C., Quist, J., Wagner, M. (2013). Sustainable innovation, business models and economic performance: an overview, Journal of Cleaner Production, 45, 18.

5. European Commission (2016): European Innovation Scoreboard 2016, available online at: http://ec.europa.eu/DocsRoom/documents/17823, accessed on: 19.10.2016 [Dataset].

6. Eurostat (2016a) Sustainable development indicators introduced, available online at: http://ec.europa.eu/eurostat/statistics-explained/index.php/Sustainable_development_ indicators introduced, accessed on: 20.10.2016 [Dataset].

7. Eurostat (2016b) Eurostat Database, available online at: http://ec.europa.eu/eurostat/ data/database, accessed on: 20.10.2016 [Dataset]. 
Pelau, C., Chinie, A. C. (2018)

Cluster analysis for the determination of innovative and sustainable oriented regions in Europe

8. Eurostat (2016c) Eurostat Database - Electricity consumption (Code: tsdpc310), available online at: http://ec.europa.eu/eurostat/tgm/table.do?tab=table \&init= 1\&language $=$ en $\&$ pcode $=$ tsdpc310\&plugin=1, accessed online: 20.10 .2016 [Dataset].

9. Eurostat (2016d) Eurostat Database - Waste Generation (Code: tsdpc210), available online at: http://ec.europa.eu/eurostat/tgm/table.do?tab=table\&init=1\&language $=$ en $\&$ pcode $=$ tsdpc $210 \&$ plugin $=1$, accessed on: 20.10.2016 [Dataset].

10. Eurostat (2016e) Eurostat Database - Air pollution (Code: tsdph370), available online at: http://ec.europa.eu/eurostat/tgm/table.do?tab=table\&init=1\&plugin=1\&pcode= tsdph370\&language $=$ en, accessed on: 20.10.2016 [Dataset].

11. Eurostat (2016f) Eurostat Database - Greenhouse gas emissions (Code: tsdcc100), available online at: http://ec.europa.eu/eurostat/tgm/table.do?tab=table\&init=1 \&language $=$ en $\&$ pcode $=$ tsdcc100\&plugin $=1$, accessed on 20.10.2016 [Dataset].

12. Eurostat (2016g) Eurostat Database - Recycling (Code: t2020_rt120), available online at: http://ec.europa.eu/eurostat/tgm/table.do?tab=table\&init=1\&plugin $=1 \& p c o d e=$ t2020_rt120\&language=en, accessed on: 20.10.2016 [Dataset].

13. Foxon, T., Köhler, J., Oughton, C. (2008). Innovation for a Low Carbon Economy: Economic, Institutional and Management Approache, Edward Elgar Publishing.

14. Hutt, R. (2016) What are the 10 biggest global challenges?, Retrieved from: https://www.weforum.org/agenda/2016/01/what-are-the-10-biggest-global-challenges/, accessed on: 20.10.2016

15. Neagu, O.; Ardelean, D.I.; Lazar, V. (2017). How Is Environmental Performance Associated with Economic Growth? A World Cross-country Analysis, Studia Universitatis Vasile Goldis Economic, Series, 27(3), 15-32.

16. Pavlovich, K. and Akoorie, M. (2010). Innovation, Sustainability and Regional Development: the Nelson/Marlborough Seafood Cluster, New Zealand, Business Strategy and the Environment, 19, 377-286.

17. Sabau, G.L. (2010). Know, live and let live: Towards a redefinition of the knowledgebased economy-sustainable development nexus, Ecological Economics, 69 (6), 11931201.

18. The Brundtland Commission Report (1987). Our Common Future, Oxford University Press

19. Turcaș, F.; Dumiter, F.; Brezeanu, P.; Jimon, S. (2016). Theoretical and Practical Issues in Business Valuation,_Studia Universitatis Vasile Goldis Economic, Series, 26(4), 1-23.

20. UN General Assembly (2015): Transforming our World: the 2030 Agenda for Sustainable Development, A/RES/70/I.

21. Vladimirova, K.; Le Blanc, D. (2016). Exploring Links Between Education and Sustainable Development Goals Through the Lens of UN Flagship Reports, Sustainable Development, 24 (4), 254-271.

Studia Universitatis "Vasile Goldis" Arad. Economics Series Vol 28 Issue 2/2018 ISSN: 1584-2339; (online) ISSN: 2285 - 3065

Web: publicatii.uvvg.ro/index.php/studiaeconomia. Pages $36-47$ 